\title{
Vascular Cognitive Disorders and Depression After First-Ever Stroke: The Fogarty-Mexico Stroke Cohort
}

\author{
Antonio Arauz ${ }^{a}$ Yaneth Rodríguez-Agudelo ${ }^{a}$ Ana Luisa Sosa ${ }^{a}$ \\ Mireya Chávez ${ }^{a}$ Francisco Paz ${ }^{a}$ Margarita González ${ }^{a}$ Juliana Coral ${ }^{b}$ \\ Claudia Díaz-Olavarrieta ${ }^{a}$ Gustavo C. Román ${ }^{c}$ \\ ${ }^{a}$ National Institute of Neurology and Neurosurgery of Mexico, Mexico City, Mexico; ${ }^{b}$ Pontificia Universidad \\ Javeriana, Bogotá, Colombia; ' Methodist Neurological Institute and Weill Cornell Medical College, \\ Houston, Tex., USA
}

\section{Key Words}

Mexico · Post-stroke depression · Stroke - Vascular cognitive disorders · Vascular cognitive impairment · Vascular dementia

\begin{abstract}
Background and Purpose: Stroke is the major cause of vascular behavior and cognitive disorders worldwide. In developing countries, there is a dearth of information regarding the public health magnitude of stroke. The aim of the Fogarty-Mexico cohort was to assess the prevalence of vascular behavioral and cognitive disorders, ranging from mild vascular cognitive impairment ( $\mathrm{VCl})$ to vascular dementia (VaD), in a cohort of acute first-ever symptomatic stroke patients in Mexico. Methods: A total of 165 consecutive, firstever stroke patients admitted to the National Institute of Neurology and Neurosurgery in Mexico City, were included in the cohort. Patients were eligible if they had an ischemic stroke, primary intracerebral hemorrhage, or cerebral venous thrombosis (CVT). Stroke diagnosis required the presence of an acute focal deficit lasting more than $24 \mathrm{~h}$, confirmed by a corresponding lesion on CT/MRI. Stroke severity
\end{abstract}

was established with the NIH Stroke Scale. The pre-stroke functional status was determined by the IQCODE. Three months after the occurrence of stroke, 110 survivor patients returned for follow-up and were able to undergo functional outcome (modified Rankin scale, Barthel index), along with neurological, psychiatric, neuropsychological, laboratory, and imaging assessments. We compared depression, demographic, and clinical and imaging features between patients with and without dementia, and between patients with $\mathrm{VCl}$ and those with intact cognition. Results: Of the 110 patients (62\% men, mean age $56 \pm 17.8$, education $7.7 \pm 5.2$ years) 93 $(84 \%)$ had ischemic strokes, 14 (13\%) intracerebral hemorrhage, and $3(3 \%)$ CVT. The main risk factors were hypertension (50\%), smoking (40\%), hypercholesterolemia (29\%), hyperhomocysteinemia (24\%), and diabetes (22\%). Clinical and neuropsychological evaluations demonstrated post-stroke depression in $56 \%, \mathrm{VCl}$ in $41 \%$, and $\mathrm{VaD}$ in $12 \% ; 17 \%$ of the latter had pre-stroke functional impairment (IQCODE >3.5). Cognitive deficits included executive function in $69 \%$, verbal memory in $49 \%$, language in 38\%, perception in $36 \%$, and attention in $38 \%$. Executive dysfunction occurred in $36 \%$ of non-demented subjects, $65 \%$ of them with mild-moderate deficits in daily living activities. Female gender $(p \leq 0.054)$,

\section{KARGER}

E-Mail karger@karger.com www.karger.com/ced
(C) 2014 S. Karger AG, Basel

$1015-9770 / 14 / 0384-0284 \$ 39.50 / 0$
Dr. Antonio Arauz

Stroke Clinic, National Institute of Neurology and Neurosurgery

Insurgentes Sur 3877, Col. La Fama

Mexico City, CP 14269 (Mexico)

E-Mail antonio.arauz@ prodigy.net.mx 
older age (mean age 65.6 years vs. $49.3, p<0.001$ ), diabetes ( $p \leq 0.004)$, illiteracy and lower education ( $p \leq 0.001)$, and PSD $(p=0.03)$ were significantly higher in VCI-VaD compared with cognitively intact post-stroke subjects. We could not demonstrate an association with lesion site and distribution of the cognitive deficits. Conclusions: The Fogarty-Mexico cohort recruited relatively young acute stroke patients, compared with other Mexican stroke cohorts. PSD and VCl occurred frequently but prevalence of $\mathrm{VaD}(12 \%)$ was lower than expected. A high prevalence of treatable stroke risk factors suggests that preventive interventions are advisable.

(c) 2014 S. Karger AG, Basel

\section{Introduction}

According to the World Health Organization (WHO), stroke is the third major cause of physical disability in adults and the second cause of death [1]. From the cognitive viewpoint, cerebrovascular disease may be the most common cause of dementia [2], found in $80 \%$ of autopsy-confirmed cases of Alzheimer's disease [3]. The prevalence of vascular dementia $(\mathrm{VaD})$ in stroke survivors is about $30 \%$ and incident dementia doubles after stroke [4]. Very few studies in developing countries have addressed the continuum of Vascular Cognitive Disorders ranging from vascular cognitive impairment (VCI) to $\mathrm{VaD}[5]$, despite higher rates of mortality and functional impairment in $\mathrm{VaD}$ patients $[4,6]$. Post-stroke $\mathrm{VCI}$ is far more common than $\mathrm{VaD}$ and often goes undetected in routine neurological assessments [7], particularly when specific cognitive areas are affected, such as executive dysfunction causing impairment of activities of daily living and delayed stroke rehabilitation. $\mathrm{VaD}$ has been associated with patient-dependent factors such as ageing, education, cognition, comorbidities, stroke characteristics, imaging features; and, most importantly, with quality of stroke care [8]. Cognitive and psychiatric assessments post-stroke are often neglected despite the prevalence of post-stroke cognitive disorders $[9,10]$.

In Mexico, there is a dearth of information regarding the public health magnitude of stroke [11] and there is no information on VCI, VaD. The aim of the Fogarty-Mexico cohort study was to assess post-stroke cognitive function in a hospital sample of Mexican stroke survivors. We hypothesize that in Mexico, vascular cognitive disorders are more frequent than in other series and that uncontrolled risk factors are the main cause of stroke in a relatively young population.

Post-Stroke Vascular Cognitive Disorders and Depression in Mexico

\section{Methods}

\section{Patients}

The study population included 165 consecutive patients with first-ever symptomatic stroke admitted to the National Institute of Neurology and Neurosurgery (NINN) in Mexico City, Mexico, between February and November 2005. Patients were eligible if they had an ischemic stroke, primary intracerebral hemorrhage or cerebral venous thrombosis (CVT). Stroke diagnosis required the presence of an acute focal deficit lasting more than 24 hours, confirmed by a corresponding lesion on CT/MRI. Stroke severity was assessed using the National Institutes of Health Stroke Scale (NIHSS) [12]. The pre-stroke functional status was determined by the IQCODE [13]. We excluded patients with prior symptomatic stroke, transient ischemic attacks, preexisting diagnosis of dementia, neurological or psychiatric diseases, or severe aphasia. As patients with subarachnoid hemorrhage are treated in Neurosurgery, they were excluded as well as patients with iatrogenic or traumatic stroke.

The 110 patients that remained in the study, three months after stroke, were survivors who returned for follow-up and were able to undergo neuropsychological testing. All cases were assessed with a comprehensive standardized battery that included medical history, laboratory tests, imaging studies (brain CT/MRI, Doppler, and angiography, if indicated), neurological and psychiatric assessments including apathy and depression scales. We classified ischemic stroke according to TOAST criteria [14] into large-artery arteriosclerosis, cardioembolism, lacunes, other causes, and stroke of undetermined etiology. Stroke location included right/left hemisphere, bilateral, anterior (carotid), and posterior (vertebrobasilar) circulation. The main outcome was cognition defined in categories of VCI to $\mathrm{VaD}$, whereas predictors post-stroke VCI were post-stroke depression (PSD), demographics, and clinical variables. Upon hospital discharge and 3 months later, patients completed the modified Rankin scale (mRs) [12] and the Barthel index (BI) [12]. Favorable outcome was defined as mRs score 0-2 and $\mathrm{BI} \geq 70$. An independent neurologist (GCR) confirmed VCI$\mathrm{VaD}$ diagnoses and a geriatric psychiatrist (ALS) reviewed the diagnosis of PSD and other neuropsychiatric symptoms.

The NINN's Internal Review Board approved the study protocol. Written informed consent was obtained from all subjects before enrollment in the study.

\section{Neuropsychological Evaluation}

A team of psychologists (YR-A, MCh, MG) administered to all testable patients a comprehensive standard neuropsychological battery adapted for Spanish-speaking population, covering all major cognitive domains, plus Beck's Depression Inventory (BDI) [15] and an apathy evaluation scale [16]. Cognitive domains tested included:

General Cognitive State: Cognitive Abilities Screening Instrument (CASI) [17] and Clinical Dementia Rating scale (CDR) [18].

Memory: California Learning Verbal Test (CVLT) [19], Wechsler Adult Intelligence Scale (WAIS-III) [20], including Wechsler Digit Span, Digit Symbol Substitution test, and block design.

Language: Controlled Word Association Test (COWAT) [21]. Executive Functions: Executive Interview Test (EXIT) [22], and CLOX, an executive clock drawing task [23].

We used the Canadian criteria for VCI without dementia [24], DSM-IV [25] criteria for dementia and NINDS-AIREN guidelines for $\mathrm{VaD}[26]$. 
Table 1. Demographic and clinical characteristics of patients

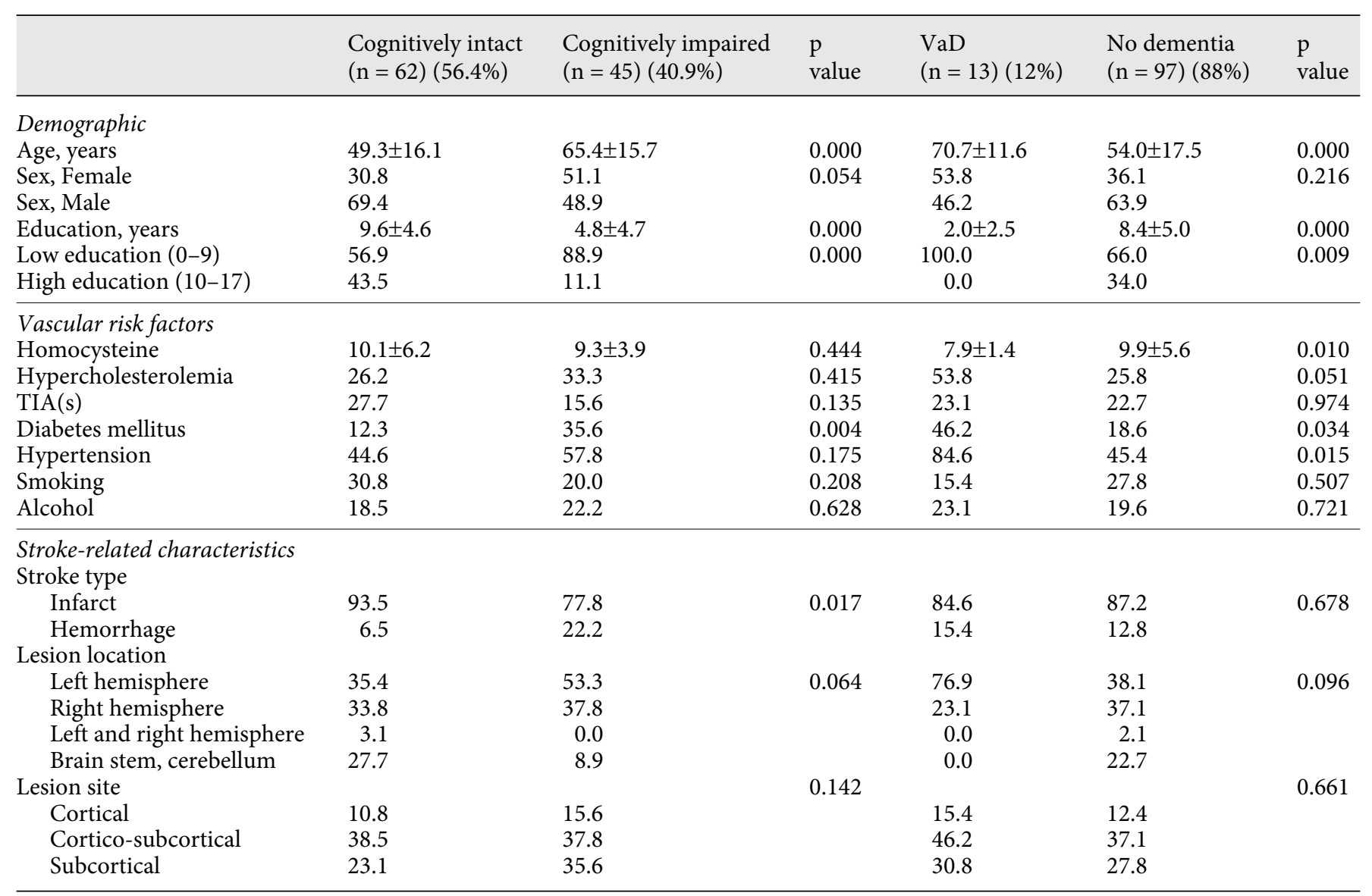

\section{Statistical Analysis}

We compared socio-demographic, clinical, and imaging features and PSD between patients with and without dementia, and between patients with VCI and those with intact cognition (table 1). Patients were classified as having VCI when they scored two standard deviations (SD) below the mean (for age, gender, and educational level) in at least one particular test. Ischemic, hemorrhagic, and venous strokes were analyzed as separate groups. Statistical analysis included chi square $\left(\chi^{2}\right)$, Fisher's exact test for categorical variables, and Student's t-test for continuous variables. Spearman method was used for correlation between functional prognosis (mRs/BI) and VaD or VCI.

We transformed neuropsychological and neuropsychiatric raw test scores into $\mathrm{z}$-scores to facilitate analyses and group comparisons. Data analysis was performed using SPSS 17 statistical package (SPSS, Inc., Chicago, Ill., USA).

\section{Results}

We examined $110 / 165$ patients (72\%) three months after the qualifying stroke (fig. 1); 68 men (62\%) and 42 women (38\%), age $56 \pm 17.8$ (range $18-85$ ), mean educa- tion $7.6 \pm 5.2$ years (range $0-17)$. There were $93(84 \%)$ with ischemic strokes, 14 (13\%) with hemorrhages, and 3 (3\%) with cerebral venous thromboses (CVT) (table 1). The main vascular risk factors were hypertension (50\%), previous and current smoking (40\%), hypercholesterolemia (29\%), hyperhomocysteinemia (24\%), and diabetes $(22 \%)$. Ischemic strokes were due to large-vessel atherosclerosis $(n=35,38 \%)$, small vessel disease $(n=21,23 \%)$, cardioembolism ( $\mathrm{n}=18,19 \%)$, non-atherosclerotic vasculopathy such as spontaneous dissections $(n=11,12 \%)$, other causes $(n=3,3 \%)$, and idiopathic $(n=5,5 \%)$. Left hemisphere strokes occurred in 47 cases (43\%), right side $(\mathrm{n}=39,35 \%)$ and 2 patients $(2 \%)$ had bilateral involvement; brainstem strokes occurred in 18 patients (16\%), 4 had cerebellar lesions (4\%); we found 14 with cortical (13\%), 31 with subcortical (28\%), 42 with cortico-subcortical (38\%), and 23 (21\%) with infratentorial lesions.

Overall, 45 patients (41\%) had VCI ranging from impairment of a single domain to multiple cognitive domains. Deficits included executive function in 69\%, verbal 


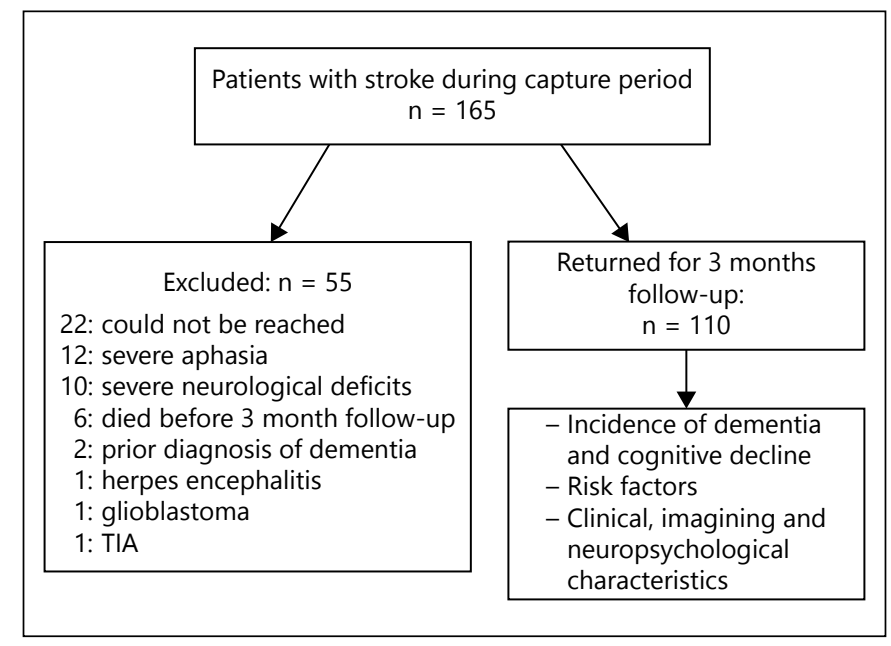

Fig. 1. Included and excluded patients during capture period.

memory in $49 \%$, language in $38 \%$, perception in $36 \%$, and attention in 38\%. Cognitively impaired patients were older than non-impaired subjects (mean age 65.6 years vs. $49.3, \mathrm{p}<0.001)$, had lower schooling attainment $(\mathrm{p}<$ $0.001)$, and were mostly women $(\mathrm{p}=0.05)$ and diabetic $(\mathrm{p}=0.004)$. The presence of PSD was associated with significant decline in cognitive tests compared with nondepressed patients $(\mathrm{p}=0.001)$. VaD patients $(\mathrm{n}=13)$ were older (mean age 70.7 vs. 54 years, $t=4.8, \mathrm{p}<0.001$ ), had less schooling $(\mathrm{p}<0.001)$, and were mostly diabetic $(\mathrm{p}=$ 0.015 ). We could not demonstrate an association between the lesion site and the distribution of the cognitive deficits.

Ischemic and hemorrhagic strokes were analyzed as separate groups. In the ischemic group $(n=93)$, the presence of $\mathrm{VaD}(\mathrm{n}=13,12 \%)$ or $\mathrm{VCI}(\mathrm{n}=45,41 \%)$ was associated with poor prognosis at 3 months post stroke $\left(\chi^{2}=5.8, \mathrm{p}=0.007\right) . \mathrm{VaD}\left(\chi^{2}=8.1, \mathrm{p}=0.004\right)$, but no VCI $(\mathrm{p}=0.3)$ was associated with diabetes. In the hemorrhagic group $(\mathrm{n}=14), 2$ cases developed $\mathrm{VaD}$ and $10 \mathrm{VCI}$; no significant associations were found, except that VCI patients had poorer outcome (mRS) at the 3-month followup. We included 3 cases with CVT and all were cognitively intact at 3 months.

PSD occurred in 56\% of our sample; 16 (14\%) had both PSD and executive dysfunction. Executive dysfunction occurred in $38 \%$ of VCI subjects and $69 \%$ of them had mild-moderate deficits in activities of daily living (ADLs). At hospital discharge, $39 \%$ of patients had a favorable functional outcome (mRS $=0-2$ ), increasing to $74 \%$ at 3 months $(\mathrm{p}<0.001)$. BI also improved significantly from hospital release to 3-month follow-up (62 vs. 90, $\mathrm{p}<0.001)$. There was correlation between adequate func-

Post-Stroke Vascular Cognitive Disorders and Depression in Mexico tional prognosis measured by $\mathrm{mRs}$ and the absence of $\mathrm{VaD}(\mathrm{r}=0.30, \mathrm{p}=0.001)$ or $\mathrm{VCI}(\mathrm{r}=0.40, \mathrm{p}=0.001)$. Higher BI correlated with the absence of VCI (BI $>70, r=$ $0.40, \mathrm{p}=0.001$ ).

\section{Discussion}

This is the first study on the prevalence of vascular cognitive disorders, ranging from mild $\mathrm{VCI}$ to $\mathrm{VaD}$, in a cohort of acute stroke patients in Mexico. We found a relatively high frequency (41\%) of VCI 3 months post-stroke, compared with $19.6 \%$ in an older cohort in Spain [27], but within the range of those reported in other case series, despite the younger age of stroke patients in this cohort from Mexico. In our study, deficits ranged from impairment of a single cognitive domain (particularly executive dysfunction) to multiple domains.

The observed frequency of $\mathrm{VaD}(12 \%)$ at 3 months post stroke is lower than the mean $\mathrm{VaD}$ prevalence $(22.8 \%)$ observed in older-patient series [28] or using different diagnostic criteria [29]. The mean age of our patients was younger ( 55.8 years) than in most series ( $\geq 60$ years-old); this is probably the result of a referral bias to a tertiarylevel stroke facility, with higher frequency of spontaneous cerebral vessel dissections [30,31], cardiac valvular lesions from rheumatic fever, CVTs, and other infrequent pathologies. Also, a high frequency (59\%) of left-sided ischemic lesions increases $\mathrm{VaD}$ risk 5-fold (OR 5.0; 95\% CI 1.9214.1) [32]. Interestingly $16 \%$ with $\mathrm{VaD}$ had evidence of pre-stroke functional impairment indicating both poor management of vascular risk factors and possible underlying Alzheimer's disease [33]. The finding of increased risk of $\mathrm{VaD}$ in older women is consistent with lower schooling among elderly women in Mexico, and also, it probably indicates the presence of mixed degenerative/vascular lesions, a very common occurrence among elderly demented patients in other ethnic groups [3]. Finally, a higher educational level appeared to be protective may be because it was associated with better functional cognitive reserve $[34,35]$. Except for diabetes, we found no association with other clinical variables or vascular risk factors.

We demonstrated an elevated frequency of PSD in $56 \%$ of patients, higher than the mean pooled estimate of $33 \%$ (95\% CI, 29-36\%) from 51 studies by Hackett and colleagues [9]. Verdelho et al. [36] found PSD in $43 \%$ of patients at 6 months post-ictus. Several studies have suggested that PSD results in worse functional stroke outcome, slow recovery, poor quality of life, and increased mortality [9, 10, 36-38]. PSD was associated with greater 
impairment at follow-up in $83 \%$ of the studies [38]. However, perhaps due to the younger age of our stroke patients, depression was not significantly associated with poor prognosis.

Sibolt et al. [39] and Vataja et al. [40] demonstrated that executive dysfunction is the core defect in patients with the depression-dysexecutive syndrome, resulting from stroke damage of frontal-subcortical circuits and are associated with a shorter interval to recurrence of ischemic stroke. In our cohort, we found $14.5 \%$ of patients with both depression and executive dysfunction.

Our study has several limitations that may hinder the generalization of results. This was a hospital-based sample and patients were recruited from a tertiary care neurological hospital where younger and more acute patients are likely to be admitted. Other selection biases include the exclusion of aphasic subjects, subjects with prior diagnosis of dementia, and the use of conservative NINDS/ AIREN criteria for the diagnosis of dementia; lastly, we had a $28 \%$ attrition rate; all these factors might have contributed to the lower prevalence of $\mathrm{VaD}$ identified in our sample. Our preliminary results require future confirmation studies with a larger sample size.

The main strengths of this study are the following: single-center cohort with prospective enrollment of sequential cases; optimal treatment of acute stroke; clear defini- tion of the type and subtype of stroke; complete clinical and radiological evaluations; systematic neuropsychological assessment with a wide battery of tests to evaluate not just memory, but multiple cognitive domains, including executive function; and, participation of a multidisciplinary team in the evaluation of the patients.

Finally, the high frequency of treatable vascular risk factors in the Fogarty-Mexico cohort, in particular, hypertension and smoking, suggests that primary prevention of stroke will require effective Public Health interventions to decrease the current mortality, morbidity, as well as cognitive and behavioral sequelae of stroke in Mexico.

\section{Acknowledgments}

The Fogarty-Mexico Stroke Cohort study was funded by a grant from the National Institutes of Health (NIH), Fogarty Center grant \# 1R21TW06786-01 'Brain Disorders in the Developing World: Research Across the Lifespan.' The authors wish to thank patients and caregivers in Mexico City for participating in the study. Dr. Erika Mariana Longoria Ibarrola provided excellent editorial assistance.

\section{Disclosure Statement}

The authors report no conflicts of interest.

\section{References}

1 WHO: World Health Organization, World Health Statistics. Geneva, Switzerland, 2013.

-2 Román G: Vascular dementia may be the most common form of dementia in the elderly. J Neurol Sci 2002;203-204:7-10.

$\checkmark 3$ Toledo JB, Arnold SE, Raible K, Brettschneider J, Xie SX, Grossman M, et al: Contribution of cerebrovascular disease in autopsy confirmed neurodegenerative disease cases in the National Alzheimer's Coordinating Centre. Brain 2013;136:2697-2706.

4 Gorelick PB, Scuteri A, Black SE, DeCarli C, Greenberg SM, Iadecola C, et al: Vascular contributions to cognitive impairment and dementia: a statement for healthcare professionals from the American Heart Association/American Stroke Association. Stroke 2011;42:2672-2713.

5 Sachdev P, Kalaria R, O’Brien J, Skoog I, Alladi S, Black SE, et al: Diagnostic criteria for vascular cognitive disorders: a VASCOG statement. Alzheimer Dis Assoc Disord 2014; 28:206-218.

-6 Miralbell J, López-Cancio E, López-Oloriz J, Arenillas JF, Barrios M, Soriano-Raya JJ, et al: Cognitive patterns in relation to biomarkers of cerebrovascular disease and vascular risk factors. Cerebrovasc Dis 2013;36:98105.

7 O’Brien JT, Erkinjuntti T, Reisberg B, Román G, Sawada T, Pantoni L, et al: Vascular cognitive impairment. Lancet Neurol 2003;2:8998.

$\checkmark 8$ Desmond DW, Moroney JT, Paik MC, et al: Frequency and clinical determinants of dementia after ischemic stroke. Neurology 2000; 54:1124-1131.

9 Hackett ML, Yapa C, Parag V, Anderson CS: Frequency of depression after stroke: a systematic review of observational studies. Stroke 2005;36:1330-1340.

10 Ayerbe L, Ayis S, Wolfe CD, Rudd AG: Natural history, predictors and outcomes of depression after stroke: systematic review and meta-analysis. Br J Psychiatry 2013;202:1421.

11 Cantú-Brito C, Majersik JJ, Sánchez BN, Ruano A, Quiñones G, Arzola J, et al: Hospitalized stroke surveillance in the community of Durango, Mexico: the brain attack surveillance in Durango Study. Stroke 2010;41:878884.

12 Kasner SE: Clinical interpretation and use of stroke scales. Lancet Neurol 2006;5:603-612.
13 Jorm AF, Jacomb PA: The Informant Questionnaire on Cognitive Decline in the Elderly (IQCODE): socio-demographic correlates, reliability, validity and some norms. Psychol Med 1989;19:1015-1022.

14 Adams HP Jr, Bendixen BH, Kappelle LJ, et al: Classification of subtype of acute ischemic stroke: definitions for use in a multicenter clinical trial. TOAST. Trial of Org 10172 in Acute Stroke Treatment. Stroke 1993;24:35-41.

15 Jurado S, Villegas M: La estandarización del Inventario de Depresión de Beck para los residentes de la Ciudad de México. Salud Mental 1998;21:26-31.

16 Marin RS: Apathy: a neuropsychiatric syndrome. J Neuropsychiatry Clin Neurosci 1991;3:243-254.

17 Teng EL: Manual of the Cognitive Abilities Screening Instrument (CASI). Versions E-1.0. Los Angeles, University of Southern California School of Medicine, 1999.

18 Hughes CP, Berg L, Danziger WL, Coben LA, Martin RL: A new clinical scale for the staging of dementia. Br J Psychiatry 1982;140:566-572.

19 Paolo AM, et al: California Verbal Learning Test: normative data for the elderly. J Clin Exp Neuropsychol 1997;19:220-234. 
20 Wechsler D, Sánchez P: Escala de Wechsler de Inteligencia para adultos. WAIS-III, ed 2. Mexico City, Manual Moderno, 2003.

21 Lezak M, Howieson D, Loring D: Neuropsychological Assessment, ed 4. New York, Oxford University Press, 2004.

22 Royall DR, Mahurin RK, Gray KF: Bedside assessment of executive cognitive impairment: the executive interview. J Am Geriatr Soc 1992;40:1221-1226.

23 Royall DR, Cordes JA, Polk M: CLOX: an executive clock drawing task. J Neurol Neurosurg Psychiatry 1998;64:588-594.

24 Rockwood K, Wentzel C, Hachinski V, Hogan $\mathrm{DB}$, MacKnight $\mathrm{C}$, McDowell I: Prevalence and outcomes of vascular cognitive impairment. Vascular Cognitive Impairment Investigators of the Canadian Study of Health and Aging. Neurology 2000;54:447-451.

25 American Psychiatric Association. Diagnostic and Statistical Manual of Mental Disorders, ed 4. Washington, DC, American Psychiatric Association, 1994.

-26 Román GC, Tatemichi TK, Erkinjuntti T, Cummings JL, Masdeu JC, García JH, et al: Vascular dementia: diagnostic criteria for research studies. Report of the NINDS-AIREN International Workshop. Neurology 1993;43: 250-260.
27 Serrano S, Domingo J, Rodríguez-Garcia E, Castro MD, Del Ser T: Frequency of cognitive impairment without dementia in patients with stroke: a two-year follow-up study. Stroke 2007;38:105-110.

28 Leys D, Hénon H, Mackowiak-Cordoliani MA, Pasquier F: Poststroke dementia. Lancet Neurol 2005;4:752-759.

29 Erkinjuntti T, Ostbye T, Steenhuis R, Hachinski V: The effect of different diagnostic criteria on the prevalence of dementia. $\mathrm{N}$ Engl J Med 1997;337:1667-1674.

30 Arauz A, Hoyos L, Espinoza C, Cantú C, Barinagarrementeria F, Román G: Dissection of cervical arteries: long-term follow-up study of 130 consecutive cases. Cerebrovasc Dis 2006 ; 22:150-154.

-31 Arauz A, Márquez JM, Artigas C, Balderrama J, Orrego H: Recanalization of vertebral artery dissection. Stroke 2010;41:717-721.

32 Pohjasvaara T, Erkinjuntti T, Ylikoski R, Hietanen M, Vataja R, Kaste M: Clinical determinants of poststroke dementia. Stroke 1998; 29:75-81.

33 Hénon H, Pasquier F, Durieu I: Preexisting dementia in stroke patients. Baseline frequency, associated factors and outcome. Stroke 1997;28:2429-2436.
34 Román GC, Nash DT, Fillit H: Translating current knowledge into dementia prevention. Alzheimer Dis Assoc Disord 2012;26:295299.

35 Willis KJ, Hakim AM: Stroke prevention and cognitive reserve: emerging approaches to modifying risk and delaying onset of dementia. Front Neurol 2013;4:13.

36 Verdelho A, Hénon H, Lebert F, Pasquier F, Leys D: Depressive symptoms after stroke and relationship with dementia: a three-year follow-up study. Neurology 2004;62:905911.

37 Paolucci S: Epidemiology and treatment of post-stroke depression. Neuropsychiatr Dis Treat 2008;4:145-154.

38 Robinson RG, Spalletta G: Poststroke depression: a review. Can J Psychiatry 2010;55:341349.

-39 Sibolt G, Curtze S, Melkas S, Pohjasvaara T, Kaste M, Karhunen PJ, Oksala NK, Vataja R, Erkinjuntti T: Post-stroke depression and depression-executive dysfunction syndrome are associated with recurrence of ischaemic stroke. Cerebrovasc Dis 2013;36:336-343.

40 Vataja R, Pohjasvaara T, Mäntylä R, et al: Depression-executive dysfunction syndrome in stroke patients. Am J Geriatr Psychiatry 2005; 13:99-107. 